\title{
Gerstmann syndrome
}

INSERM

\section{Source}

INSERM. (1999). Orphanet: an online rare disease and orphan drug data base. Gerstmann syndrome. ORPHA:221117

Gerstmann syndrome is a very rare neurological disorder characterized by the specific association of acalculia, finger agnosia, left-right disorientation, and agraphia, which is supposed to be secondary to a focal subcortical white matter damage in the parietal lobe. 